\title{
潤滑剂結合力と磁気ディスク耐久性
}

Effect of Bond Strength between Lubricant and Carbon Surface on Durability of Rigid Disk

林 真一、川本淳、山岸浩一、金井塚 唯人

住友金属鉣山（株）中央研究所、千葉罢市川市中国分3-18-5（尔2 $72 ）$

S. Hayashi, A. Kawamoto, K. Yamagishi, T.Kanaizuka

Central Research Lab. Sumitomo Metal Mining Co., Ltd. $3-18-5$ Nakakokubun I chikawa Chiba 272

The effects of the bond strength between lubricant and carbon surface on the durability of rigid disk(CSS and stiction) are studied. In this study, we focused on two parameters:time interval between carbon sputtering and lubricant coating, and curing temperature of the lubricant.

It was found that both the bond strength and the durability were obtained as functions of these two parameters, then the durability relates strongly to the strength of the bond.

To control the strength of the bond accurately and to improve the durability, it is necessary to take into account the effect of the time interval. From this point of viev, new technique of the curing system on the manufacturing is possible.

Key words: rigid disk, lubricant, curing, CSS, durability, stiction, contact angle.

1.はじめに

固定㻂気ディスク装置では、装管の始動や停止に伴 いッッドがディスに接触し擦れ合うコンタクト・スタ 一ト・ストップ（CSS）方式が採用されている。磁気 ディスク装置の信頼性を向上させる上でCＳＳに対する 耐久性向上は重要な課題である。これは主にディスクノ ヘッド間の摩擦特性亡吸着特性の問題で、磁気ティスク 表面に塗布される潤滑膜の特性に強く依存する。最近の 磁気へッドの低浮上化はより優れた耐久性を要求するこ とになり、したがって耐久性を向上させるへく潤滑特性 の制御の精密化が重要課題となってきている。これまで

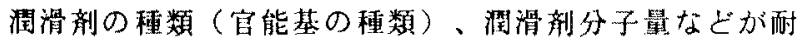
久性に及ぼす影噌については調へられてきたがい、っ、 潤滑膜の形成条件が耐久姓に及ほす影留については検討 されていなかった。今回我々は力ーボン保護膜を有する スパッ夕型磁気ティスクにおいて洞滑膜形成条件、特に

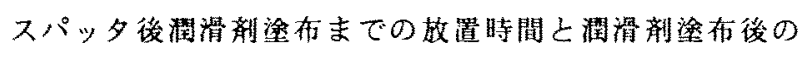
堵成が潤滑剂とカーボン保護膜との結合力に影变を与え ている事を見いだし、その絬合力が耐久性に与える等動 について明らかにしたので報告する。

\section{2. 実雅方法}

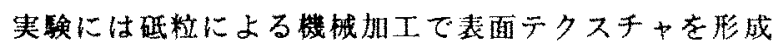
したA $1 / \mathrm{NiP}$ 基板上にC $\mathrm{C} / \mathrm{C}$ oCrTa/ C 三層 膜をスパッ夕法により形成した酸気ィスクを用いた。 淍滑刘には、水酸基を官能基として有するパーフルオ口 アルキルポリエーテル系润滑敦 $(\mathrm{z}-\mathrm{d} 01$ ，モンテカ チー二社製）を用い、パーフルオロアルキル系溶媒( ロリナート F C - 7 7，3 M 社慗）以潤滑剂を溶解さ せスピンコート法により塗布、その後オーブンによる焼

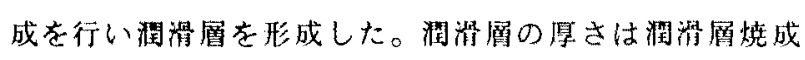
後の测定で、全ての実験において $33 \pm 1.5 \mathrm{~A}$ とる ように湴布時の浱度を調整した。

㳗有された澗滑剂分子とカーボン保護膜との粘合力、 結合割合を次の上うな洗浄試呀を行う方法で简显に評価 した。洞滑膜を形成した磁気ディスクを上㲹溶媒（FC 77 ) で 3 分間超音波洗浄し、洗浄前後の榈滑膜厚の比 を洞滑剂残存率として定義し、こ扎をもって結合力の指 標とした。淍滑剂残存率が高いほど、カーボンとの高い 結合力持ち溶媒に溶出しない潤滑郕份子の割合が多いと 考える。 
淍滑膜厚仙XPS（X線光電子分光）で測定したCー $C$ 結合 $(285 \mathrm{eV}) 、 \mathrm{C}-\mathrm{F}$ 結合 $(292 \mathrm{eV})$ のピ 一ク比より以下の換算式より計算した。

$$
\delta=40 \cdot \ln \left\{3.1 \cdot\left(I_{C-F} / I_{C-C}\right)+1\right\}
$$

C S S 試験は單板酎久性試驗器（KT 202 , 交洋製 作所製)を用いて行った。測定条件は荷重的 $9 \mathrm{~g} の 70$ $\left.\% \mathrm{~A}\right|_{2} \mathrm{O}_{3}$ ・T i C スライダーを有するへッド、立ち上 がり及び乱ち下がり時閪 3 秒、最高回転数 $3.6 \mathrm{~m} / \mathrm{s}$ （浮上限界速度䄪 $3 \mathrm{~m} / \mathrm{s}$ ) 、停止及び定常回轻時間無 しとした。立ち上がり、立ち下がり時の回転数の変化パ ターンを Table1に示すが、可能な限り長くディスタと ヘッドが摺動するように回転パターンを設定した。CS Sによる動攀擦係数の変化を定期的に湘定し、勤知擦係 数の1周中の最大值が 0.4 を越えたときを故障と定義 した。そのときのCSS回数より累皘八ザード法を用い たワイブルプロットを行い、平均故障 C S S 回数を求め た。測定面数は8-12 面とした。

吸着試験はＣＳＳ試験と同じ仕様のヘッドを用いて

Table 1 Rotaonal speed pattern for CSS.

Rising

\begin{tabular}{|c|c|c|c|c|c|c|}
\hline time $(\%)$ & 10 & 20 & 40 & 60 & 80 & 100 \\
\hline rot. speed $(\%)$ & 20 & 30 & 38 & 45 & 60 & 100 \\
\hline
\end{tabular}

Lowering

\begin{tabular}{|c|c|c|c|c|c|c|}
\hline time( $(x)$ & 10 & 30 & 50 & 80 & 90 & 100 \\
\hline rot. speed $(x)$ & 78 & 50 & 42 & 30 & 20 & 0 \\
\hline
\end{tabular}

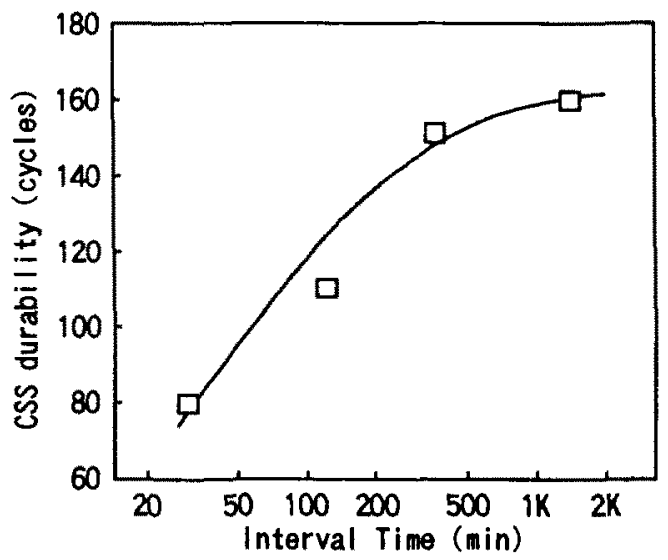

Fig. 1 CSS durability as a function of time interval between sputtering and lubricant coating.
$80{ }^{\circ} \mathrm{C} 、 80 \%$ RHの垣温恒湿環境化に 48 時間放䁂後 の静止最大摩擦係数を測定し求めた。吸着試呀の測定面 数は 8 面とした。

3. 結果、考察

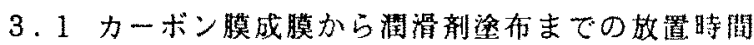
の影斐

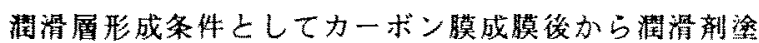
布までの故置時間が耐久性に与える影䇾について摆へだ。 スパッ夕成膜された基板をクリーンルーム中 (2 $3{ }^{\circ} \mathrm{C} 、$ $50 \% \mathrm{R} \mathrm{H})$ に一定特閻放置し、その後F T P(ファイ ナルテープポリッショ）、洞滑剂叙布、焼成を連続して 処理した。焼成条件は焼成温度 $100{ }^{\circ} \mathrm{C}$ 、焼成時間は 5 0 分とした。Fig，1にこの放置時間によるC S S 酎久性 の変化を示す。洞滑㖉有までの放置時間が長くなるにし たがい、故障までの平均 CSS 回数が增加し C S S 耐久 性が向上する。淍滑染布までの放置中にCS S 耐久性に 影㹕を及ぼすような何らかの装化がディスクに生したと 考えられる。

C S S 耐久性が放置時間に上り变化する原因を洞滑郕 とカーボンとの結合力の観点から調へた。Fig. 2 に洗浄

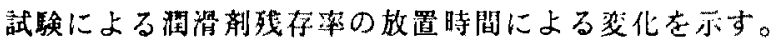
洞滑剂残存率は放置時間とともに隇少する。放置時間が 30 分では残存率は7 0 \%と高率であるが、充分長時間

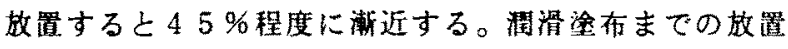
時間が長くなるに従い減滑剂分子とカーボン表面との結 合力が低下することが示された。この結果はカ一ボンの 表面状態が放置中に潤滑剂との結合を阻害するように变 化したことを示している。

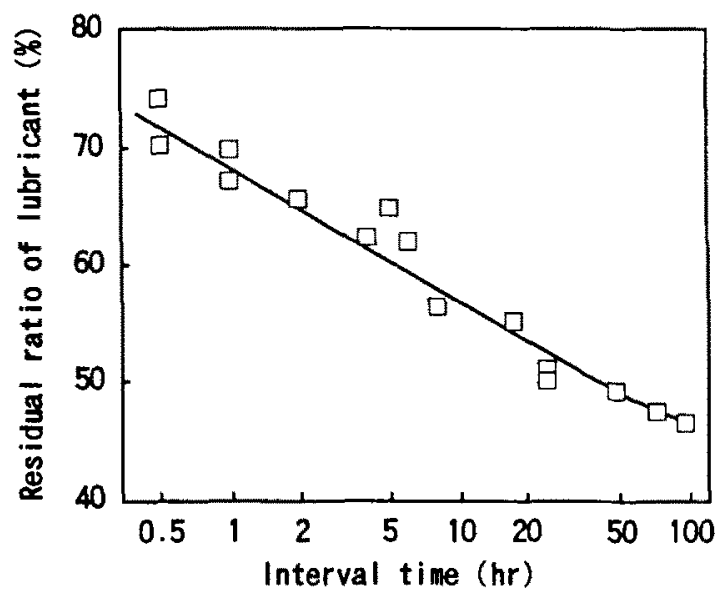

Fig.2 Lubricant residual ratio versus time interval between sputtering and lubricant coating. 


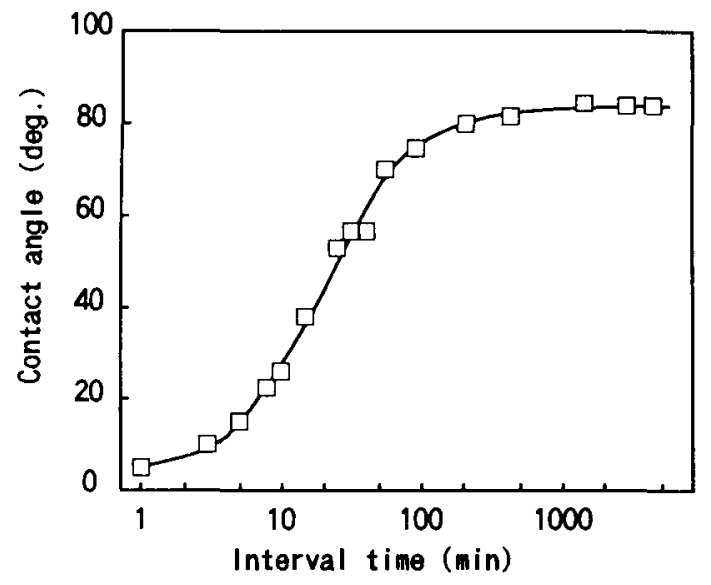

Fig.3 Time interval dependence of contact angle on carbon surface.

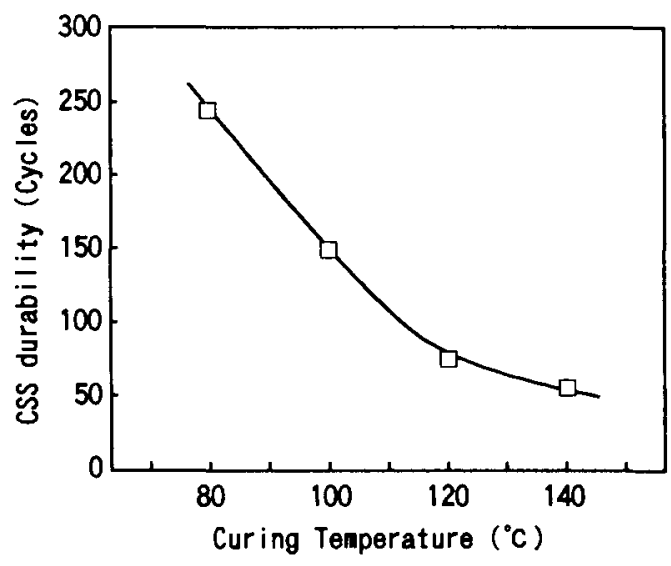

Fig.4 Curing temperature dependence of CSS durability (in oven).

カーボン表面に対する $\mathrm{H}_{2} \mathrm{O}$ の接触角の放置時間によ る変化を調べた結果をFig. 3 に示す。カーボン表面はス パッ夕直後には接触角が数度と小さく非常に濡れ性が良 いが、時間とともに濡れ性が低下し充你長時間放置後 （24 時間以降）には接触角は約 85 度となる。この接 触角の変化からも潤滑剂の結合力に影整するカーボンの 表面状態の変化が時間とともに生じていることが支持さ れる。つまりスパッ夕直後のカーボン表面は活性度が高 くこの状態では潤滑剂分子との結合が生じ易くその結合 力が強いが、時間が立つにつ机カーボン表面の活性が失 わ机潤滑剂分子との結合が生じ難くその結合が弱くなる。 表面の活性が失われる原因は空気中の炭化水素などによ るカーボン表面の污染、あるいは酸素、室素などによる カーボン表面の䇂飾などではないかと推測される。また、 この接触角の変化は次に述べような嫃成では回復せず、 強固な化学結合が形成されていると思える。

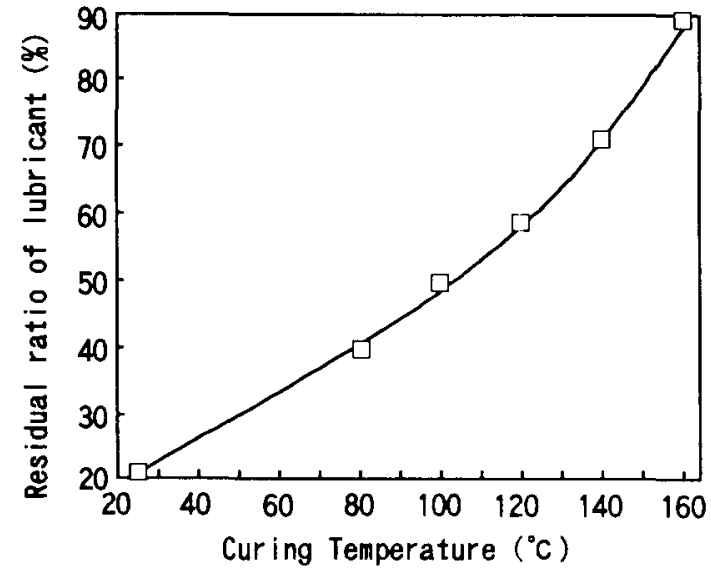

Fig.5 Curing temperature dependence of lubricant residual ratio (in oven).

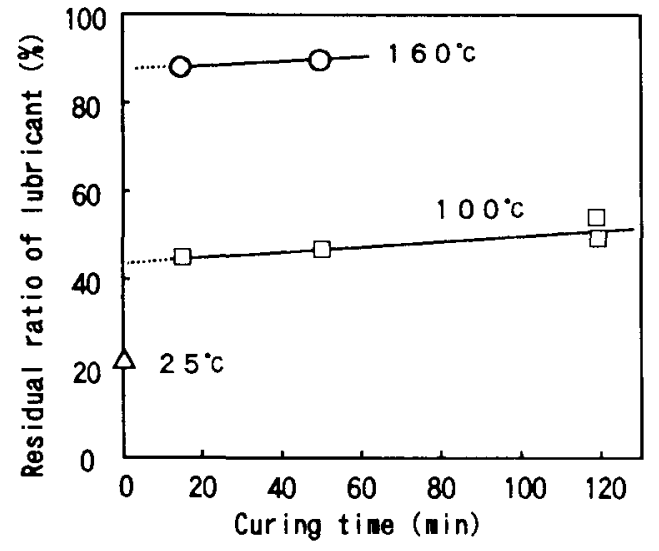

Fig.6 Curing time dependence of lubricant residual ratio (in oven).

これらの結果は安定した C S S 耐久性を得る上でカー ボンの表面状態を制御することが重要な問題であること を示唆している。

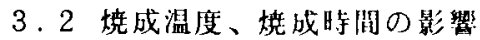

洞滑膜形成条件として洞沿剂塗布後の焼成温度及び㜔 成時間が耐久性に及ほす影響について示す。スパッ夕成 膜さ扎た基板をクリーンルームけ（2 $\left.3{ }^{\circ} \mathrm{C} 、 50 \% \mathrm{R} \mathrm{H}\right)$ に24 時間放置し、その後 F T P、睡消剂塗布、焼成を 連続して处理した。Fig. 4 に㳳成湓度とCS S 耐久性の 関係について、Fig. 5 に焼成温度による結命力の変化を 示す。この時の焼成时間は全て 50 分とした。Fig. 4、 5より焼成温度が高いほどC S S 耐久性が少り、それと 同時に洞滑剂の結合力が強くなっていることが分かる。 前項の結果と同样に焼成温度も洞消剂の結合力を関して C S S 耐久性に影留を与えている上考えられ。 


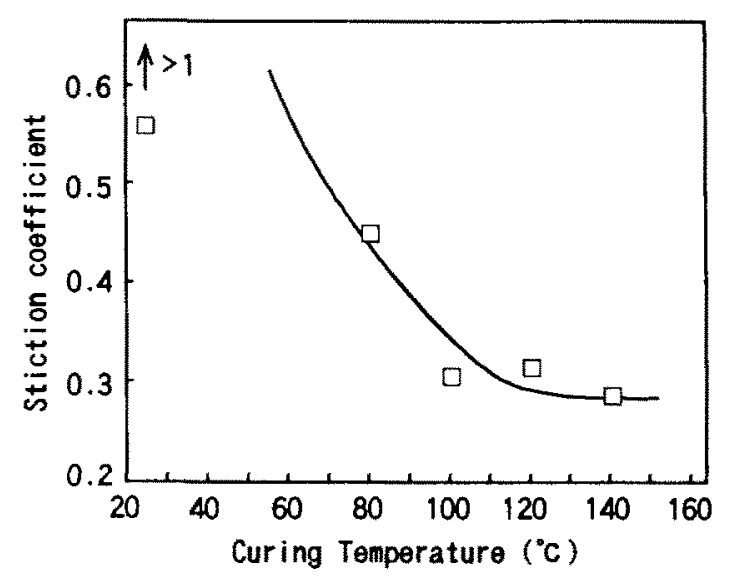

Fig.7 Curing temperature dependence of stiction coefficent (in oven).

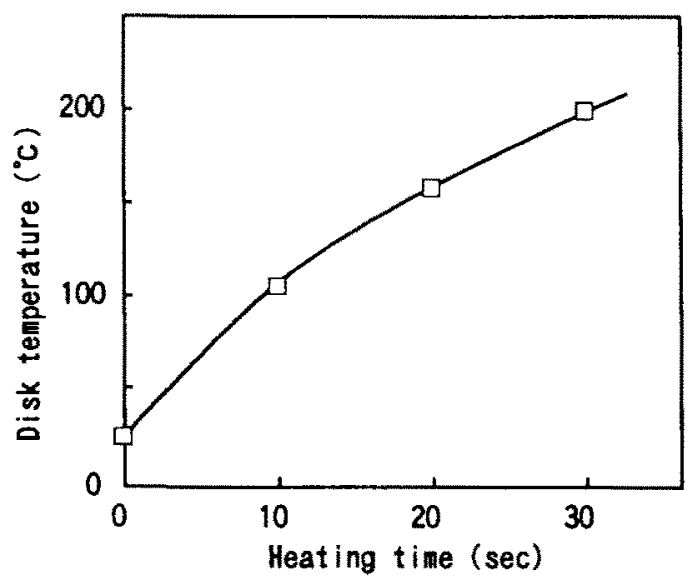

Fig. 8 Heating time dependence of disk temperature using IR heater.

Fig. 6 に焼成時間と阔滑剂結合力の関係についての測 定結果を示す。焼成時間が長くなると若干は結合力が增 加する傾问は諗められるが、15分から120 分の閻で は時間にはは上んど侤存しない。オーブン投入後ディス クが昨温するまでの時閏を考虑にいれると、短時間（ 15 分以内）の内にその温度で結合するほとんどの結合 が完了すると言え、結合力はほとんど焼成鼬度にのみ传 存し時間には依存しない。つまり洞滑剂と力ーボンの結 合様式は一樣ではなく、したがってその反応の活性化工 ネルギーも単一ではなく分布がある(種々のエネルギー 值をとる)ため反応率が温度にのみ依存する結果が得ら れたと考えられる。

\section{3 結合力之耐久性の関係}

以上のように润滑剂の結合力と C S S 酎久性は密接な 関係にあることが理解される。更にFig. 7 に燎成時間と

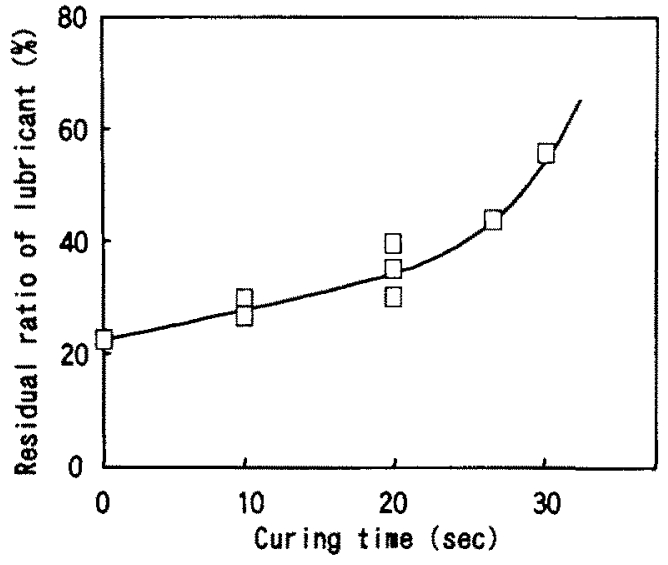

Fig.9 Curing time dependence of residual ratio using IR heater.

吸着特性の関係を示す。Fig. 5 の烧成時間と結合力の関

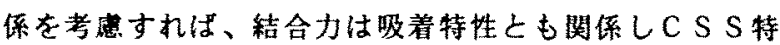
性とは逆に結合力が高いほど吸着特性が良いことがわか る。結合力とＣＳＳ、吸着特性の関係は次のように考え られる。润䯈剂とカーボン表面の結合力が強いと洞滑剂 分子のカーボン表面で移動が少なく吸着現象の原因之 なるメニスカスの形成が起こりにくい"゙。しかし、C S

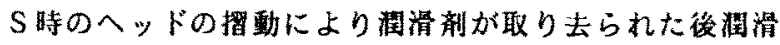
剂が復元するいかゆる自己修復作用が弱〈なるい〉。従。 て、吸着特性は改善されるがCS S 特性は少化する。結 合力が弱い場合は上述とは逆のメカニズムで吸着特性が 墨化しCSS特性が改善される。

\section{4 焼成方法の改善}

次に耐久性に優れた阔滑層を安定に効率よく形成する プロセスについて考える。今までの㦈論で明らかになっ たように淍滑剂の密着力が時間に刘して変化し、そ机に つれて耐久性も変化することから、娍滑特性を掅密に制 御するためにはスパッ夕終了後潤滑剂塗布までの時間を 規定したプロセスが重要と考えられる。しかし、バッチ 式の烧成工程では大量のティスクを一括して処理するた め焼成までの時間を全てのティスクで間一にすることは 難しい。そこで、赤外線ヒータによる輻射で急速にデ スクを加熱する枚梯式（ディスクを一枚ずつ処理する） の焼成装置を用い従来のバッ千式焼成如による万法と比 敕した。泪滑治布までの放置時間は24特間とし、放器 時間のばらつきが結果に影敕しないようにした。

Fig. 8 に示されるように赤外線加熱装置を用いると 30 秒以内にディスクを $100{ }^{\circ} \mathrm{C}$ 以上に加熱できる。こ の時の洞骴剂の結合力と加熱時間の関係をFig. 9 に示す 
が、最高到達温度 $1300^{\circ} \mathrm{C}$ ，加熱時間 15 秒の焼成条 件の時に、従来の暁成护での $1000^{\circ} \mathrm{C} ， 50$ 分と同等の $50 \% の$ 結合力を示した。同一の結合力を示す温度が焼 成如による加熱と異なるのは、急速昇温による温度測定 の誤差、あるいは加熱されている時間が結合反応に必要 な時間に比較して短いためと思われる。そこで亦外線輻 射加熱、1 $30{ }^{\circ} \mathrm{C} 、 15$ 秒の条件で焼成したティスクに ついてそのCS S、吸着特性を調へた。Table 2 にその 結果を従来の焼成妒を用いた方法と合わせて示すが赤外 楾輻射加熱による焼成は從来の焼成如に上る方法と同等 のCS S、吸着特性を示すことがかかった。 よって、赤外線輻射加熱を用いた枚様式の烧成工程を 取り入れることで放置時間を正確に制御し耐久性の安定 したディスクを効率よく生産できることがかかった。

Table 2 Comparison of durability cured by IR heater with that by oven.

\begin{tabular}{|l|c|c|}
\hline & CSS (cycles) & Stiction \\
\hline $\begin{array}{l}\text { IR Heater } \\
\left(130^{\circ} \mathrm{C}, 15 \mathrm{sec}\right)\end{array}$ & 220 & 0.32 \\
\hline $\begin{array}{l}\text { Oven } \\
\left(100^{\circ} \mathrm{C} .50 \mathrm{~min}\right)\end{array}$ & 160 & 0.30 \\
\hline
\end{tabular}

4.まとめ

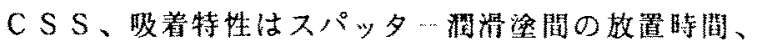
湖清膜焼成温度に強く依存し、それは洞滑剂とカーボン の結合力によって説明される。

閏滑叙布までの放置時間を規定し、赤外線による枚葉 式の加熱方法を用いることで耐久性の安定したディス夕 を效率よく生産できる。

\section{文献}

1)A. H. Scarati and G. Caporiccio : IEEE Trans. Hagn. MAG-23, 106(1987)

2)B. Bhushan and U. T. Dugger : J. Trib., Trans. ASUE111. $452(1990)$

3). J. Mat thewson and H. J. Mamin : Proc. Mat. Res. Soc. Symp. $119.87(1988)$

4)Y. Hu., and F. E. Talke: "Tribology and Hechanics of Magnetic Storage Systems" Vol.5.pp.43-48. SP-25, STLE, Park Ridge, Illinois. 